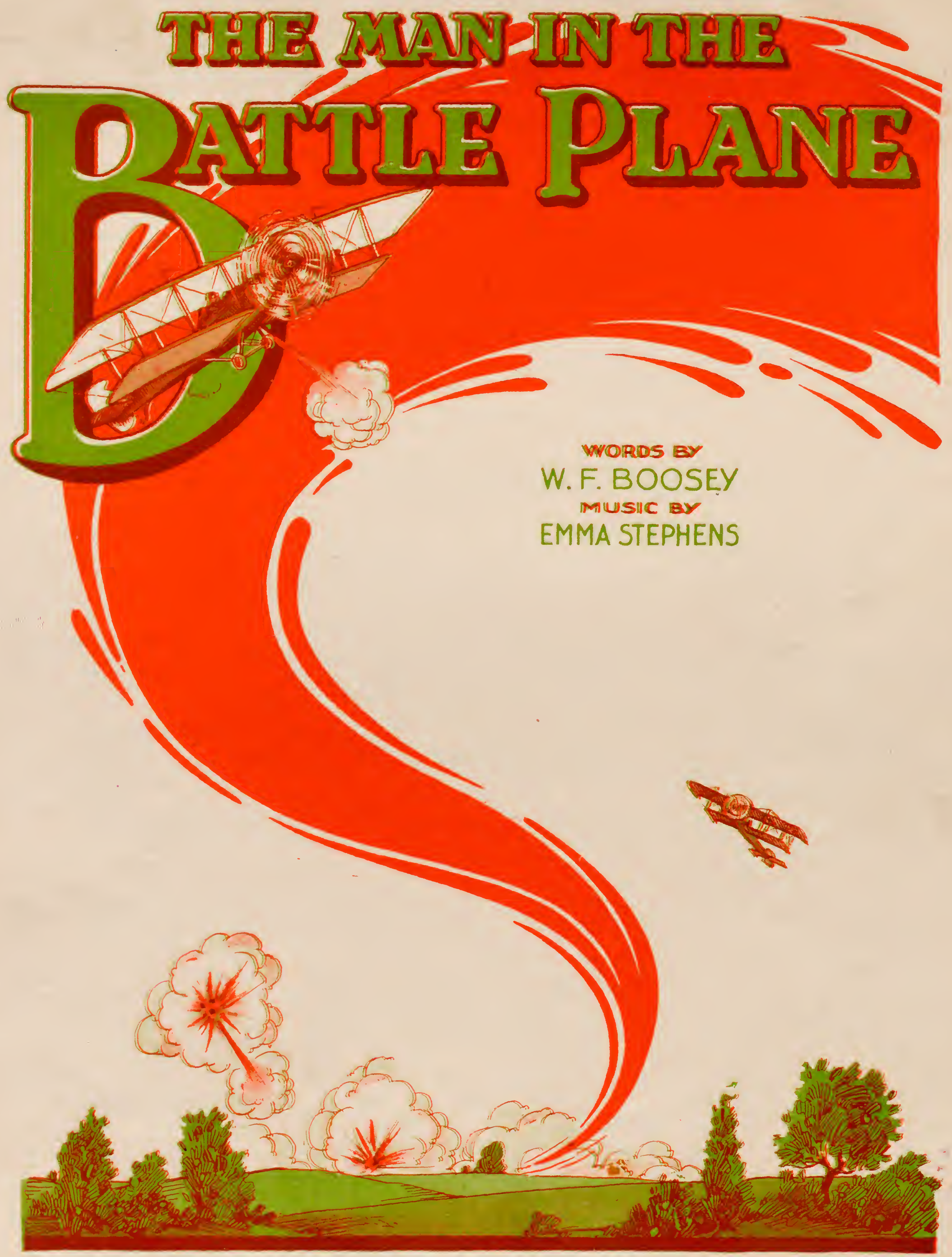

T. B. HARMS

6 MRANOLS. DAND \& MUNMTER 

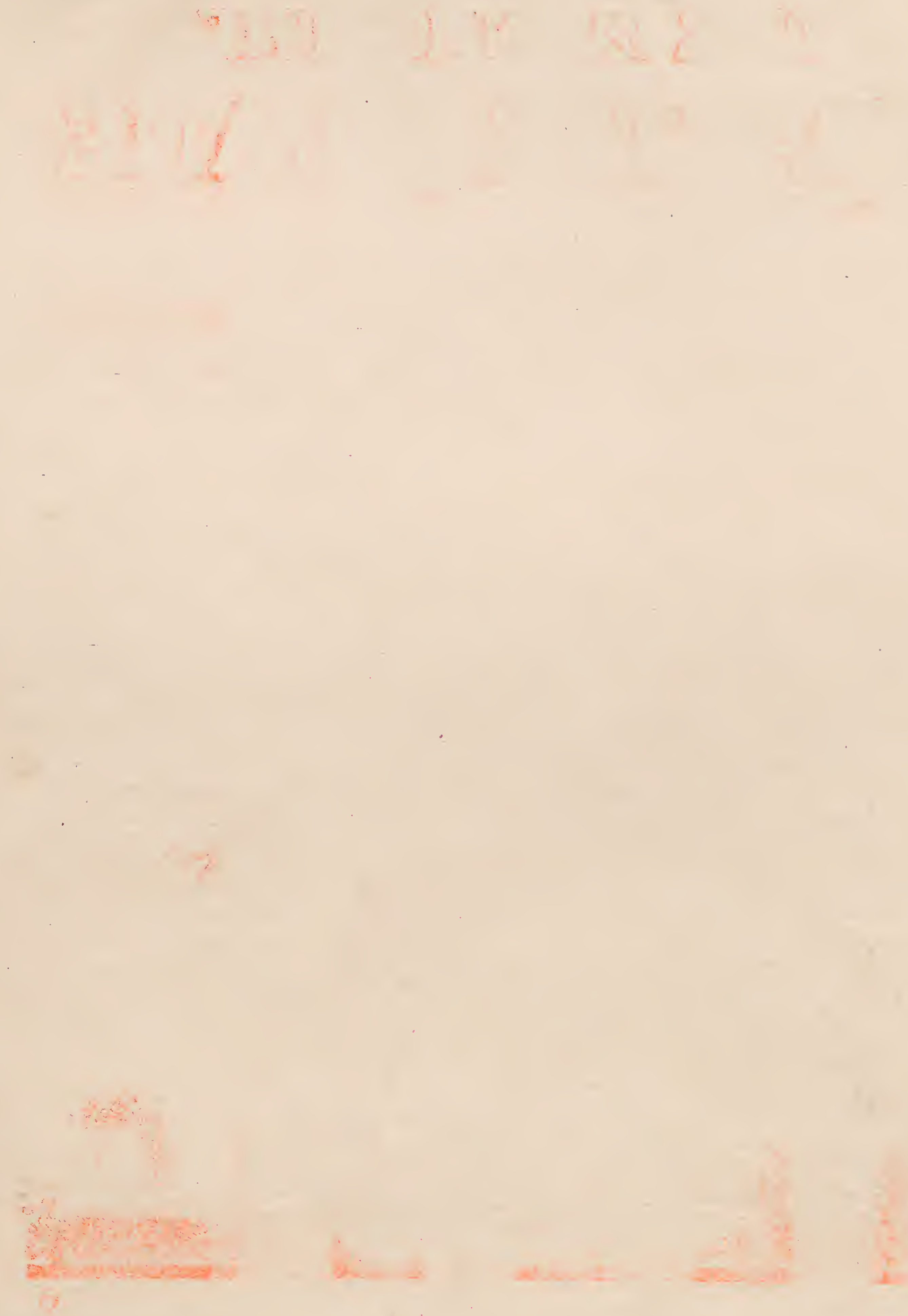


\section{The Man In The Battle Plane.}

Lyric by

W. F. BOOSEN.
Music by

EMMA STEPHENS.
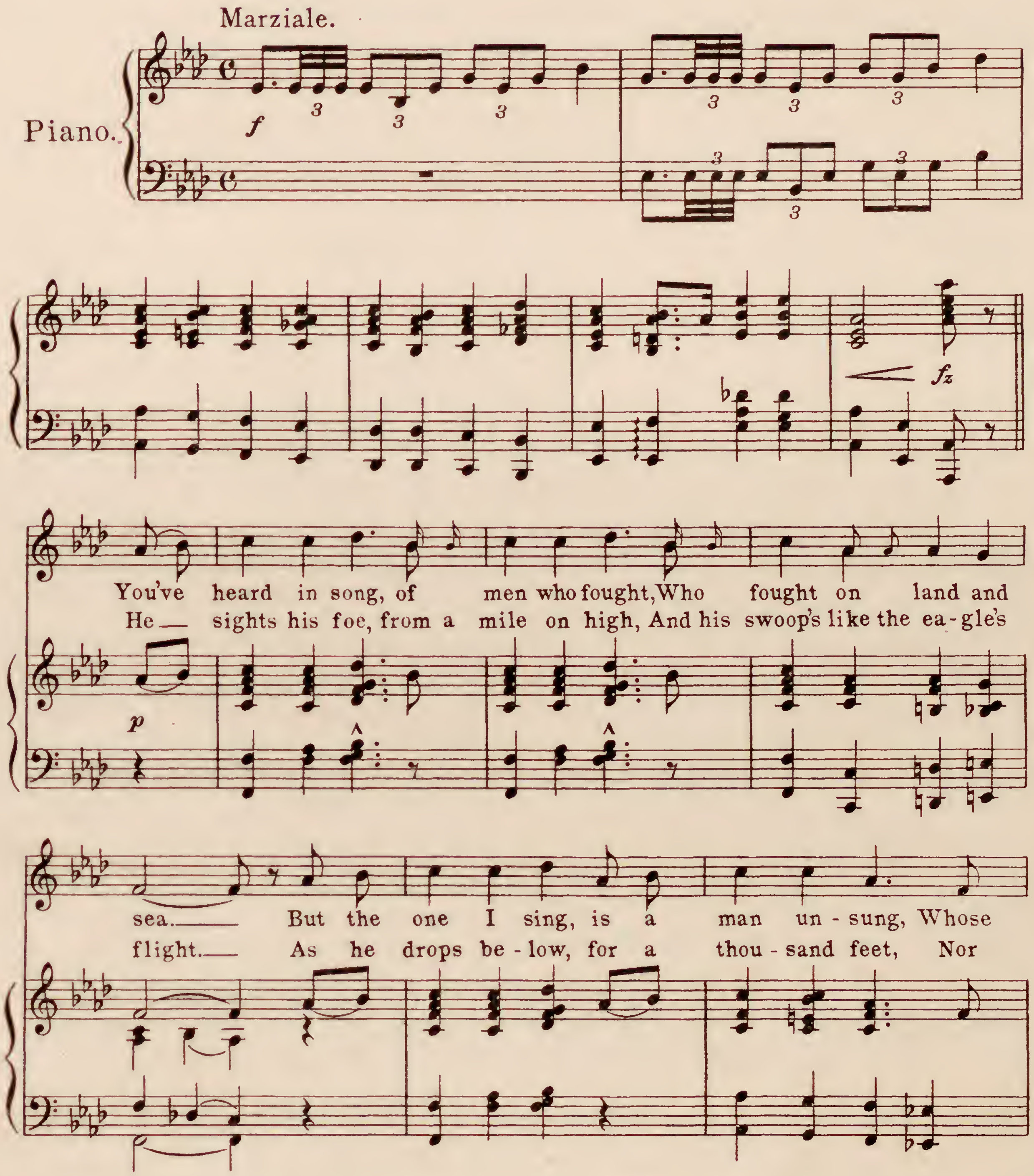

$5561-3$

Copyright MCMXVII by T. B. Harms \& Francis, Day \& Hunter, N. Y.

All Rights Reserved.

International Copyright Secured. 
4

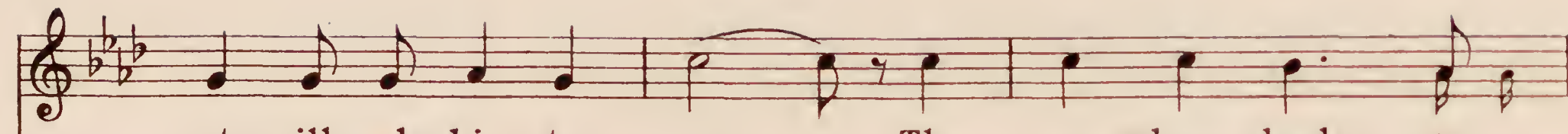
acts will make his - to - ry.__ The one whose deeds, sur thinks of his foe-man's might._. He breathes a prayer, for his
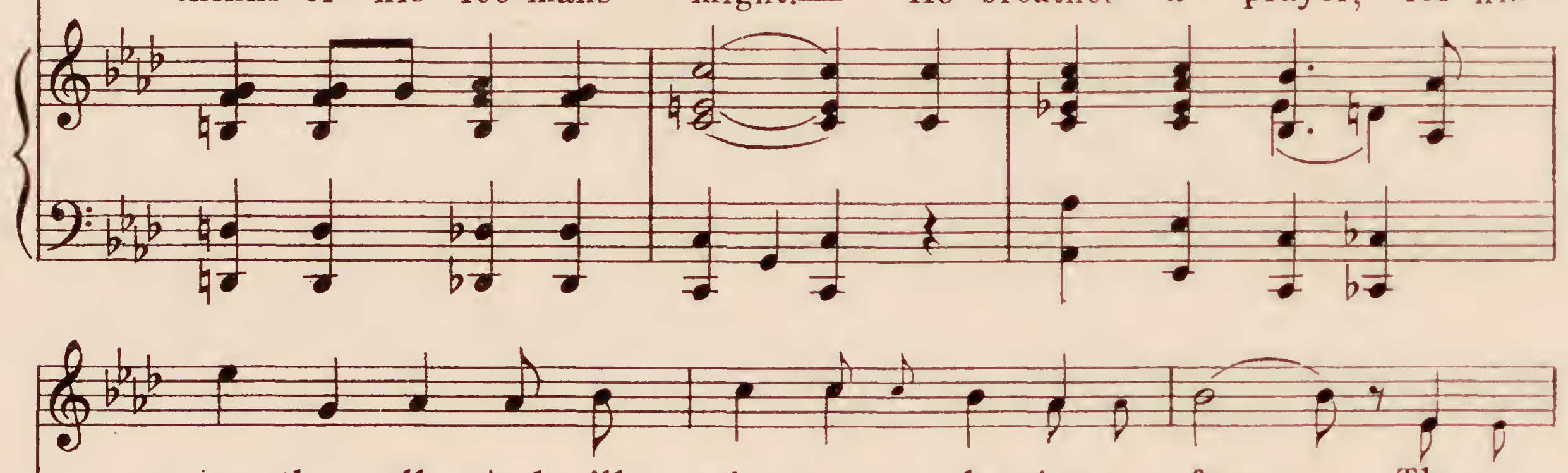
-pass them all And will win un - dy-ing fame._- The coun-try's care And the ones he may neer see a - gain._. Then he
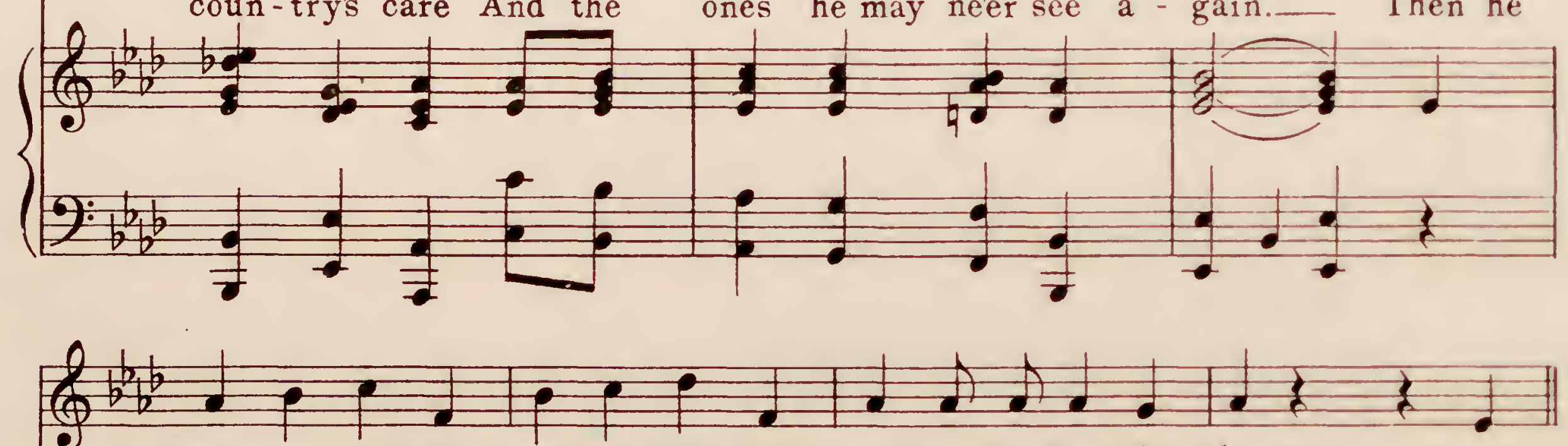
man whofights the brav-est fight, The man in the bat-tle plane. plung-es on to do or die, The man in the bat-tle plane.

Like
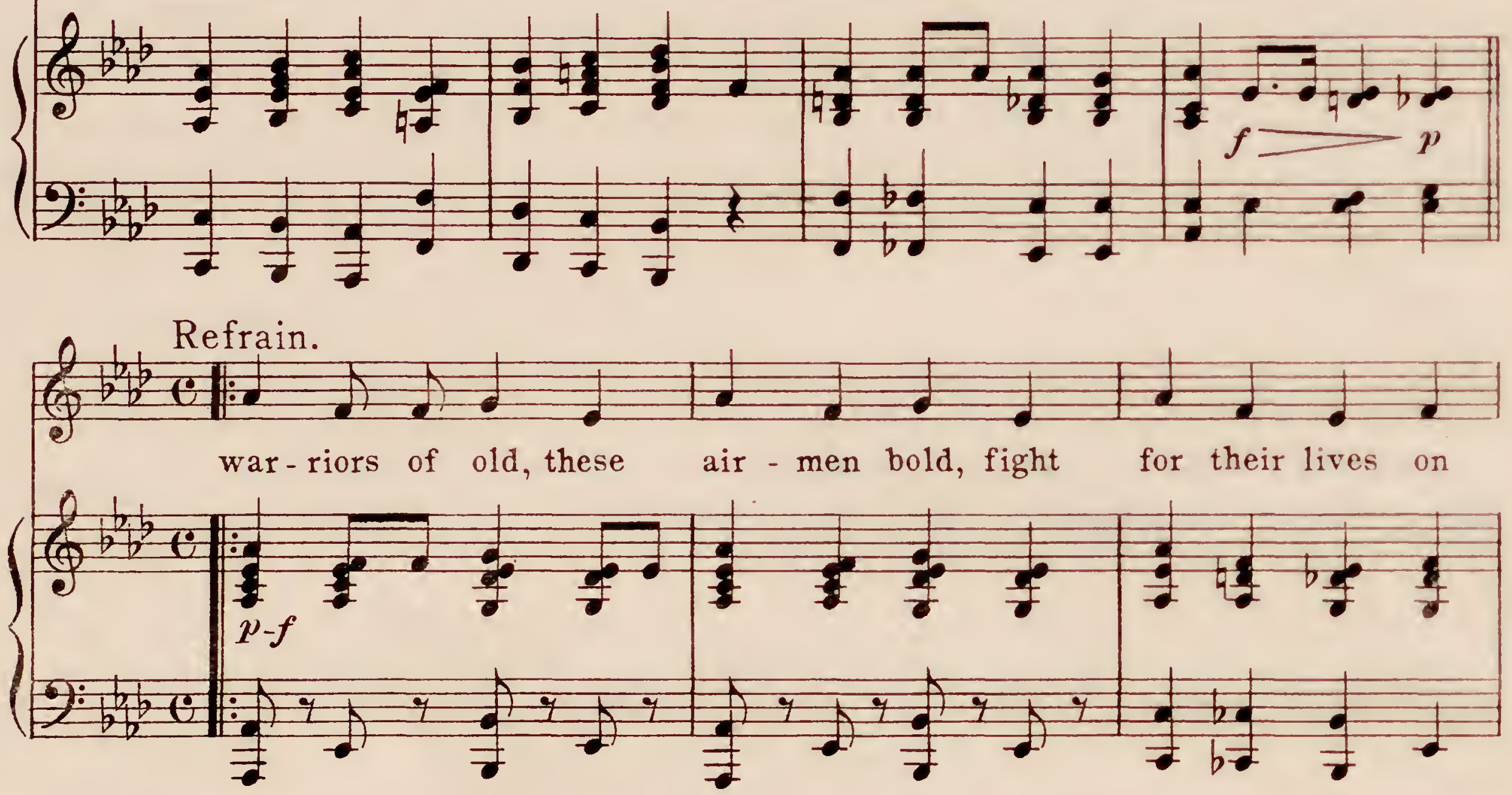

5561_3 The Man In The Battle Plane. 

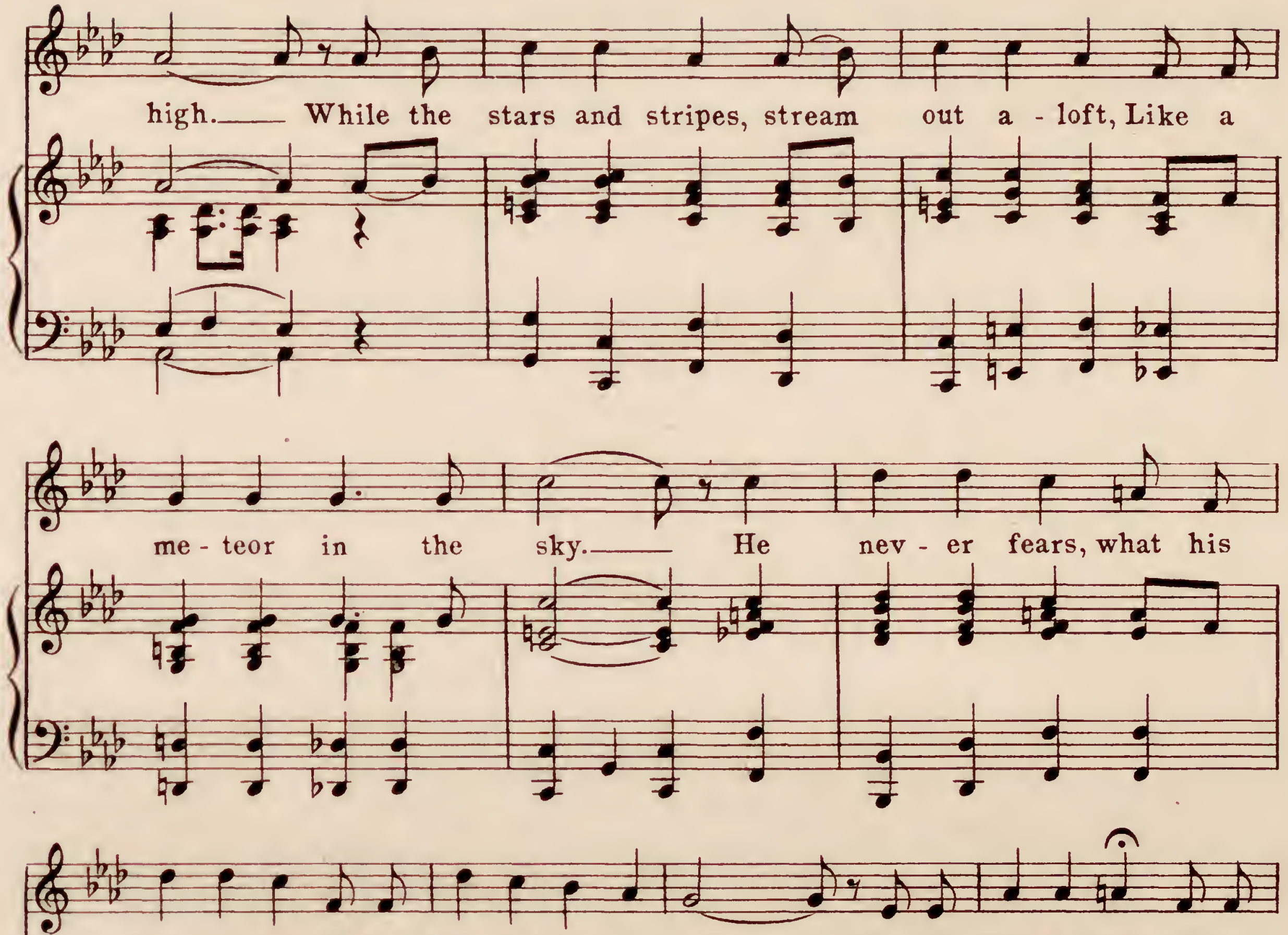
fate may be, If he fails he tries a - gain.__ For his life be-longs, to the
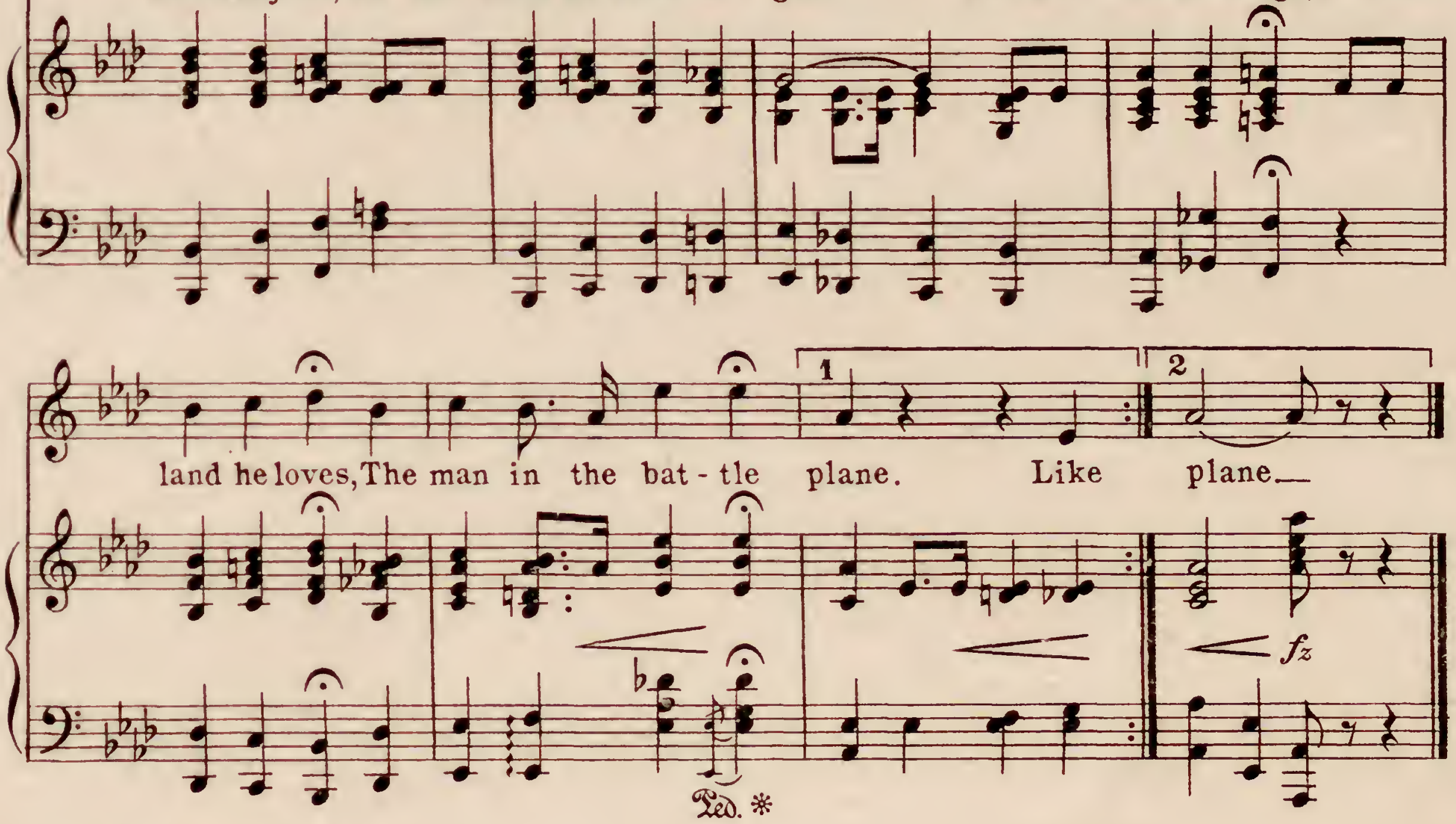

5561 - 3 The Man In The Battle Plane. 
Wurds by Sometime Youll Rememlor. "yw ".s RAYMOND WALLACE.
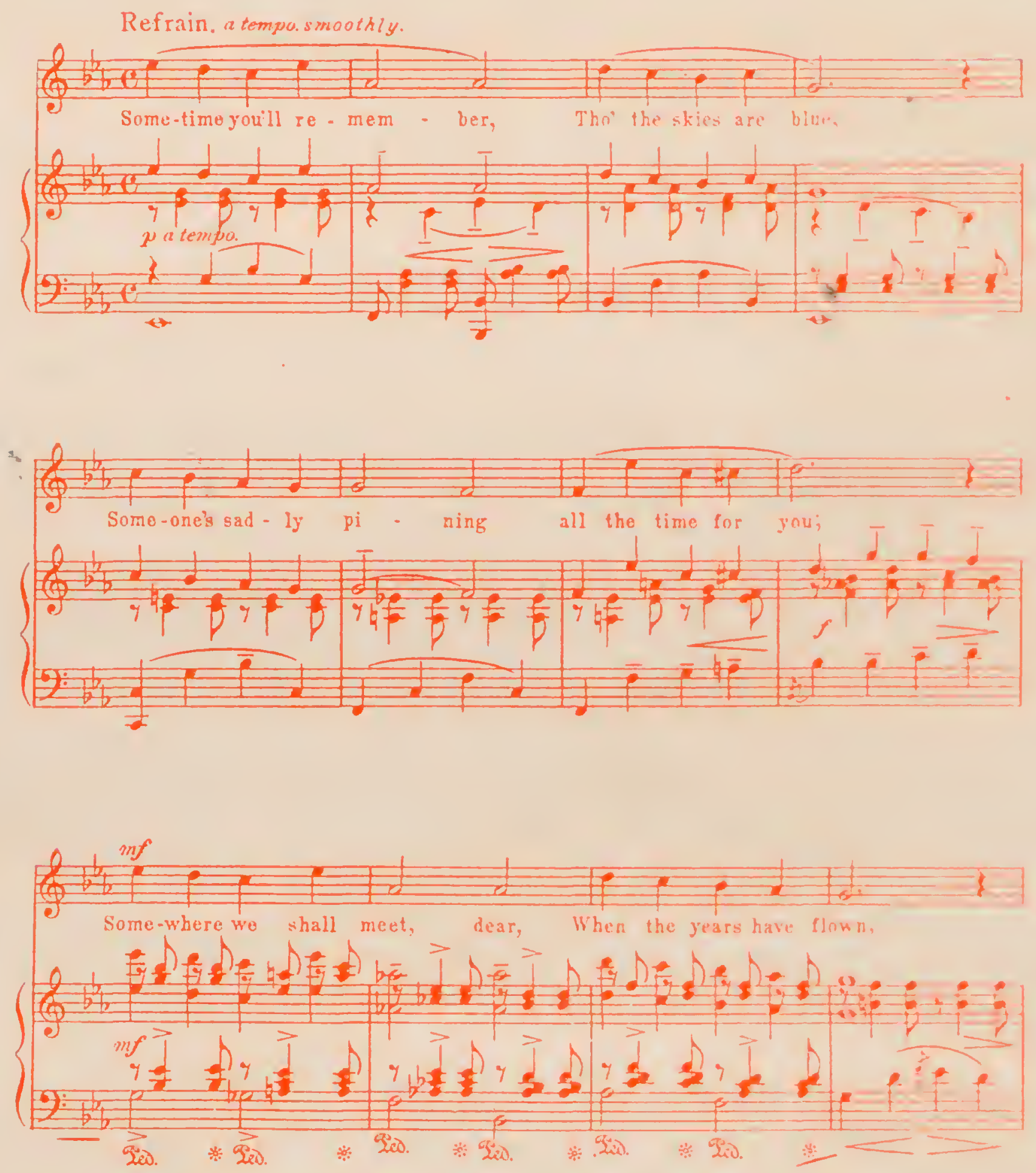

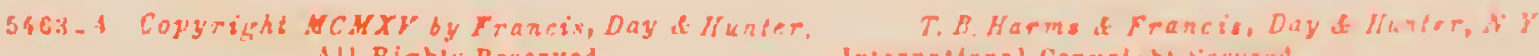
All Righis Reserved. Iuternablonal Conyrighs secured.

For sale by all dealers 